\title{
Efficacy and Safety of Combination of NSAIDs and Muscle Relaxants in the Management of Acute Low Back Pain
}

\author{
Himanshu D. Patel - R. B. Uppin - A. Ramakrishnam Naidu • \\ Y. Ratnakar Rao · Suhas Khandarkar · Amit Garg (D)
}

Received: October 31, 2018 / Published online: January 16, 2019

(C) The Author(s) 2019

\section{ABSTRACT}

Introduction: Low back pain is a common problem worldwide causing deterioration of health and quality of life. Low back pain is often associated with muscle spasm. We investigated the combined effect of muscle relaxants and pain killers for low back pain.

Methods: In this open-label, prospective, multicenter study, patients with acute low back pain received a single tablet of either the fixed

Enhanced Digital Features To view enhanced digital features for this article go to: https://doi.org/10.6084/ m9.figshare.7565696.

H. D. Patel

Nirmal Hospital Pvt Ltd., Ring Road, Surat, Gujarat 395002, India

R. B. Uppin

KLE University's JN Medical College and KLES Dr Prabhakar Kore Hospital and MRC, Nehru Nagar, Belagavi, Karnataka 590010, India

A. R. Naidu

Department of Medicine, King George Hospital, Maharanipeta, Vishakhapatnam, AP 530002, India

Y. R. Rao

Nagarjuna Hospital, DrNo.8-108, Kanuru,

Vijaywada, AP 520007, India

S. Khandarkar · A. Garg $(\square)$

Global Medical Affairs, Dr Reddy's Laboratories Ltd, 8-2-337, Road No 3, Banjara Hills, Hyderabad 500034, India

e-mail: amitgarg.pharm@gmail.com dose combination of chlorzoxazone $500 \mathrm{mg}$ and ibuprofen $400 \mathrm{mg}$ (manufacturer: Dr. Reddy's Laboratories, India) (C + I group) or ibuprofen $400 \mathrm{mg}$ (I group) thrice daily for up to 7 days. Primary outcomes were improvement in pain by Visual Analogue Scale (VAS) and Summed Pain Intensity Difference (SPID) at 3 and 7 days post-treatment.

Results: A total of 406 patients were included in this study. When compared to baseline, the absolute mean change in VAS scores on Day 7 was $62.39 \pm 18.78$ and $57.34 \pm 16.29$ in the $\mathrm{C}+\mathrm{I}$ and I groups, respectively $(P=0.0001)$. In the $\mathrm{C}+\mathrm{I}$ and I groups, the mean SPID at Days 3 and 7 were $51.27 \pm 24.44$ and $47.80 \pm 22.91$, and $300.82 \pm 92.40$ and $277.16 \pm 81.83$, respectively. No deaths or serious adverse events were reported. Common adverse events included gastritis, stomach pain, fever, cold, and headache. At the end of the study, excellent to good response was reported in $94.08 \%$ and $77.33 \%$ of patients in the C + I and I groups, respectively. Excellent to good tolerability was observed in $96.05 \%$ and $89.65 \%$ patients in the two groups, respectively.

Conclusion: Fixed dose combination of chlorzoxazone and ibuprofen demonstrated superior efficacy than ibuprofen monotherapy in acute low back pain. Both drugs were well-tolerated and should be considered as judicious therapeutic options in patients with acute low back pain. 
Trial Registration: This trial is registered with Clinical Trial Registry of India-CTRI/2016/10/ 007348.

Funding: Dr. Reddy's Laboratories Ltd.

Keywords: Anti-inflammatory agents; Chlorzoxazone; Low back pain; Non-steroidal; Ibuprofen; Spasm

\section{INTRODUCTION}

Low back pain (LBP) is a common problem with global lifetime prevalence of approximately $38.9 \%$. The highest incidence of LBP is reported in the third decade of life with increasing prevalence until 60-65 years [1]. Age, obesity, educational status, psychosocial, and occupational factors play a major role in the development of back pain. It is usually associated with muscle spasm. LBP can have a negative impact on general health, quality of life, and functional ability. It also causes a socio-economic burden on patients, physicians, and healthcare due to disability and work absenteeism [1].

LBP is disabling, frequently episodic and persistent, and is associated with increased healthcare utilization and high costs [2, 3]. For patients who seek medical care, various options are available- non-steroidal anti-inflammatory drugs (NSAIDs), acetaminophen, skeletal muscle relaxants, antidepressants, opioids, and physical therapy [1]. Treatment is aimed at interrupting the perpetuating cycle of painspasm-pain [4].

According to the American College of Physicians [5] and National Institute for Health and Care Excellence (NICE) guidelines [6], NSAIDs are recommended as the most beneficial treatment for acute LBP. Skeletal muscle relaxants are generally considered as adjunct therapy for acute LBP when initial therapy fails [7].

For optimal effect, high doses of NSAIDs and muscle relaxants are required. At such high doses, NSAIDs cause gastric intolerance while centrally acting muscle relaxants are associated with sedation, mental confusion, dizziness, weakness, and impairment of coordination. Thus, an ideal fixed dose combination (FDC) which can overcome these limitations is highly desirable [8]. One such combination of the muscle relaxant chlorzoxazone $500 \mathrm{mg}$ and the NSAID ibuprofen $400 \mathrm{mg}$ was approved in India in 2010 for short term treatment of musculoskeletal pain associated with inflammation and spasm in adults. The component ibuprofen and chlorzoxazone in this FDC have complementary actions and relieve pain and spasms in patients with musculoskeletal disorders.

Higher effectiveness for short-term pain relief has been reported with the addition of skeletal muscle relaxant to paracetamol or an NSAID than with the analgesics alone [9-12].

In a double-blind study in 53 outpatients with painful skeletal muscle spasm, chlorzoxazone was found to be significantly more effective than diazepam with fewer side effects [13]. Ibuprofen has an established efficacy for pain relief. Superior analgesic effects have been reported with ibuprofen $400 \mathrm{mg}$ when compared to acetaminophen $1000 \mathrm{mg}$ in several clinical pain conditions [14]. In the Paracetamol, Aspirin, and Ibuprofen New Tolerability study (PAIN study), ibuprofen (up to $1.2 \mathrm{~g} /$ day) for 7 days was as well-tolerated as paracetamol and had better tolerability than aspirin $[15,16]$.

Currently, no experience has been published for the effectiveness of chlorzoxazone and ibuprofen in the treatment of LBP in the Indian population. Hence, the present study was done to compare the efficacy and safety of the FDC of chlorzoxazone and ibuprofen versus ibuprofen alone in patients with acute LBP clinically suspected to be associated with muscle spasm.

\section{METHODS}

\section{Study Characteristics}

This was an open-label, multicenter, parallelgroup, prospective study conducted across four centers in India between August and December 2016. The study was comprised of a baseline visit and two study visits at Days 3 and 7 .

The study was conducted in accordance to the Declaration of Helsinki, Good Clinical Practice, and the ethical guidelines for biomedical research on human participants. 
Informed consent was obtained from all individual participants included in the study. Additional informed consent was obtained from all individual participants for whom identifying information is included in this article. The study protocol and subsequent amendments to the same were approved by the Institutional Ethics Committees of all study centers. This trial is registered with Clinical Trial Registry of India-CTRI/2016/10/007348.

\section{Inclusion and Exclusion Criteria}

Males and females between 18 and 60 years of age attending the outpatient services for acute LBP and clinically confirmed muscle spasm were included in the study. Patients with pain of less than 3 days in duration and with or without radiation to the knee were included.

Patients who received any skeletal muscle relaxants in the last 2 days and those with other lumbar or cervical spinal tract conditions (e.g., spondylitis, fracture, cancers, severe arthritis and osteoporosis), muscular diseases (e.g., myositis, polymyositis, muscular dystrophy and myotonia), or any systemic disease affecting the nervous or endocrine systems were excluded. Patients with previous or current cardiovascular disorders, uncontrolled diabetes mellitus or any other metabolic disorder; patients with moderate to severe hepatic failure, renal failure, bulimia, hypo and hyperthyroidism, nephrotic syndrome, anorexia nervosa, and biliary obstruction were excluded. Patients with active or recent history of inflammatory diseases of the gastrointestinal tract, and those with allergic manifestations due to salicylic acid or NSAIDs were also excluded from the study.

After detailed medical history and clinical examination, patients meeting the eligibility criteria were enrolled into the study at the discretion of the investigator. Laboratory assessments were conducted if deemed essential by the investigator.

\section{Treatment Allocation and Follow-Up}

Patients received thrice daily dosing with a single tablet of the FDC of chlorzoxazone
$500 \mathrm{mg}$ and ibuprofen $400 \mathrm{mg}$ (manufacturer: Dr. Reddy's Laboratories, India) or ibuprofen $400 \mathrm{mg}$. The tablets were administered $30 \mathrm{~min}$ after meals for a period of 7 days. For uncontrolled pain with the study medication alone, rescue medication with acetaminophen $500 \mathrm{mg}$ was permitted during the study.

The patients did not receive any other treatments apart from the study medication prescribed. Only other medications used by patients were either for adverse events (pantoprazole, ranitidine, omeprazole, paracetamol, chlorpheniramine) or concomitant illnesses (antihypertensive medications, oral hypoglycemic agents, or insulin). Other medications included supplements with calcium, folic acid, and multivitamins.

Patients were instructed to adhere to the prescribed regimen and ensure intake of medication 30 min after major meals. To ensure data completeness and minimize data loss due to failure of patients to visit for follow-up visits, telephonic communication was carried out by the investigator or research assistant from the sites. In an event of failure of the patient to visit the site, telephonic data capture was carried out only for one follow-up visit.

\section{Study Outcomes}

\section{Primary Efficacy Outcomes}

Pain during movement was assessed on a 0-100 mm Visual Analogue Scale (VAS) $2 \mathrm{~h}$ after the morning dose on days 0,3 , and 7 . Changes from baseline in Summed Pain Intensity Difference (SPID) were also determined.

\section{Secondary Efficacy Outcomes}

Changes from baseline in Total Pain Relief (TOTPAR), Finger-to-Floor Distance (FFD), muscle tension/tone, night discomfort, and the effect of pain on daily functions were assessed on Days 3 and 7. Presence or absence of limitation in movement and sensory symptoms were also recorded. Global Assessment of Response to Therapy (GART) was assessed on Day 7.

The SPID, an indicator of cumulative analgesic effects of the study drugs on pain 
intensity, was assessed at $2 \mathrm{~h}$ post-dosing. Relief in pain was assessed on a 5-point categorical scale; $0=$ No relief and $4=$ Complete relief. After dosing, TOTPAR 0-2 and TOTPAR 0-3 scores were defined as sum of pain relief ratings at 1 and $2 \mathrm{~h}$ (Score range: 0 [worst] to 8 [best]) and sum of pain relief ratings at 1,2 , and $3 \mathrm{~h}$ (Score range is 0 [worst] to 12 [best]), respectively. A higher value in TOTPAR was indicative of greater pain relief [17].

FFD, an index of lumbar spine mobility, was assessed in the standing position with spinal cord flexed and complete extension of knee joint measured. The distance between tip of the middle finger to the surface of the floor was measured in millimeters ( $\mathrm{mm})$ [18].

Lumbar and dorsal hypermyotonia was assessed by palpation of the lumbar paravertebral muscles with patient at rest lying in prone position. Severity of hypertonia and restriction in movement were recorded using a four-point rating scale; $0=$ No hypertonia, $1=$ Mild hypertonia, 2 = Moderate hypertonia, slight restriction of movement, and $3=$ Marked hypertonia, marked restriction of movement.

Discomfort due to pain in the night was assessed by the numbers of night awakenings.

Effect of pain on daily functions was assessed on a five-point Likert scale; $0=$ No pain or movement restriction), $1=$ Mild pain with no restriction of function, $2=$ Moderate pain with some function restriction, $3=$ Severe pain with significant function restriction, $4=$ Extreme with complete function restriction. Improvement in sensory disturbances (tingling, numbness, and paresthesia) was reported as 'Present' or 'Absent'. All these parameters were assessed on days 3 and 7 compared to baseline. Clinicians made the GART assessments using a 5-point scale; $1=$ Excellent Response, $2=$ Good Response, $\quad 3=$ Average Response, $\quad 4=$ No Response, 5 = Worse Response.

\section{Safety Outcomes}

Safety outcomes included adverse events (AEs) and serious adverse events (SAEs) that were spontaneously reported by the patients or identified by clinicians during the study. Vital signs were recorded at all study visits. Laboratory assessments (complete hemogram and liver function tests) were done on investigator discretion. The AEs were classified by system-organ-class (MedDRA classification of medical terminology). The severity of AEs was classified as mild, moderate, or severe depending upon no, minor, or marked limitations of daily activities, respectively. Decisions for withdrawal from the study for drug-related AEs were made by investigators at the study centers. Patients' compliance with the study medication was recorded on Days 3 and 7. At the end of the study, Global Assessment of Tolerability to Therapy (GATT) was independently assessed by the patients and physicians on a 5-point scale; 1 = Excellent tolerability, 2 = Good tolerability, 3 = Moderate tolerability, $4=$ Poor tolerability, $5=$ Worst tolerability.

\section{Statistical Analysis}

To detect a mean difference of $\geq 0.5$ [19] between two groups for SPID-3 score, with an assumed standard deviation of $1.6,80 \%$ power, and significance level 5\%, a sample size of 324 patients was required. Assuming a dropout rate of $25 \%, 406$ patients were enrolled in the study with equal distribution in both the groups.

Statistical analysis was based on the intention-to-treat principle, and $p<0.05$ was considered significant. Two sample $t$ test or Wilcoxon rank sum test for continuous data and Chi squared test for categorical data were used to compare the baseline characteristics between the two groups. Statistical analysis of all the outcome variables was conducted with the analysis of covariance (ANCOVA)/ $t$ test.

A descriptive analysis of demographic characteristics was performed. Absolute change in mean VAS score, mean FFD score, and mean number of night awakenings, from baseline to day 3 and day 7 were analyzed by the Paired $t$ test. The SPID was derived from the VAS score for Day 1 (SPID—01), Day 3 (SPID—03) and Day 7 (SPID—07). Other secondary efficacy variables were analyzed descriptively.

Safety endpoints were analyzed for the safety population. AEs and GATT were summarized with the use of descriptive statistics for all 
patients who received at least one dose of active study treatment.

\section{RESULTS}

A total of 406 patients (203 patients each in the $\mathrm{C}+\mathrm{I}$ group: Chlorzoxazone and Ibuprofen group and I group: Ibuprofen group) were recruited in this study. There were no patient drop outs or withdrawals during the study period. All patients complied by the study procedures and completed the study. The demographic details are presented in Table 1.

\section{Primary Efficacy Outcomes}

Mean VAS scores at baseline, and Days 3 and 7 are shown in Fig. 1. When compared to baseline, the absolute mean change in VAS scores at day 3 was $33.76 \pm 15.70(31.58,35.92)$ and $31.08 \pm 14.71(29.04,33.11)$ in the $\mathrm{C}+\mathrm{I}$ and I groups, respectively $(P=0.0767)$. Similarly, the change on Day 7 was $62.39 \pm 18.78$ $(59.79,64.98)$ and $57.34 \pm 16.29(55.08,59.59)$, respectively $(P=0.004)$.

In the $\mathrm{C}+\mathrm{I}$ and I groups, the mean SPID at Days 3 and 7 were $51.27 \pm 24.44$ and $47.80 \pm 22.91$, and $300.82 \pm 92.40$ and $277.16 \pm 81.83$, respectively.

\section{Secondary Efficacy Outcomes}

\section{Post-Dose Pain Relief}

Proportion of patients with pain after first dose of medication at baseline was assessed after first, second and third $\mathrm{h}$ using TOTPAR score. At $1 \mathrm{~h}$ after dosing, $0.49 \%$ of patients in $\mathrm{C}+\mathrm{I}$ group

Table 1 Demographic and baseline characteristics

\begin{tabular}{lll}
\hline & $\mathbf{C}+\mathbf{I}(\boldsymbol{N}=\mathbf{2 0 3})$ & $\mathbf{I}(\boldsymbol{N}=\mathbf{2 0 3})$ \\
\hline Age (years), Mean $\pm \mathrm{SD}^{*}$ & $43.30 \pm 11.14$ & $41.30 \pm 11.26$ \\
Females, $n(\%)^{*}$ & $120(59.11 \%)$ & $117(57.64 \%)$ \\
Weight $(\mathrm{Kg})$, mean $\pm \mathrm{SD}^{*}$ & $67.30 \pm 11.95$ & $66.40 \pm 11.57$ \\
Height $(\mathrm{cm})$, mean $\pm \mathrm{SD}^{*}$ & $162.70 \pm 09.99$ & $162.90 \pm 7.05$ \\
Underweight & $13(6.40 \%)$ & $12(5.91 \%)$ \\
Normal weight & $80(39.41 \%)$ & $85(41.87 \%)$ \\
Overweight & $87(42.86 \%)$ & $90(44.33 \%)$ \\
Obese & $23(11.33 \%)$ & $16(7.88 \%)$ \\
Vital sign parameters, Mean $\pm \mathrm{SD}$ & & $78.80 \pm 7.64$ \\
Pulse (/min) & $80.50 \pm 7.33$ & $123.40 \pm 8.03$ \\
Systolic blood pressure $(\mathrm{mm} \mathrm{Hg})$ & $124.30 \pm 8.09$ & $78.50 \pm 5.81$ \\
Diastolic blood pressure $(\mathrm{mm} \mathrm{Hg})$ & $80.00 \pm 5.95$ & $18.80 \pm 2.27$ \\
Respiratory rate $(/ \min )$ & $18.50 \pm 2.27$ & $74(36.45 \%)$ \\
Concomitant medications $n(\%)$ & $68(33.50 \%)$ & $14(6.90 \%)$ \\
Medical disorders n $(\%)^{\mathrm{a}}$ & $20(9.85 \%)$ & \\
\hline
\end{tabular}

${ }^{a}$ Includes patients with diabetes, hypertension, and gastrointestinal disorders

\% Percentage, BMI Body mass index, $C m$ Centimeter, $K g$ Kilogram, $m$ meter, $S D$ Standard deviation, $C+I$ Chlorzoxazone + Ibuprofen, I Ibuprofen alone, $B M I\left(\mathrm{Kg} / \mathrm{m}^{2}\right)$ Underweight: $>18.5$, Normal weight 18.5-24.9, Overweight 25.0-29.9, Obese $>30$

${ }^{*}$ No significant differences in two treatment groups. $P$ values: age: 0.07 ; females: 0.96 ; height: 0.95 ; weight: 0.43 ; BMI: 0.94 


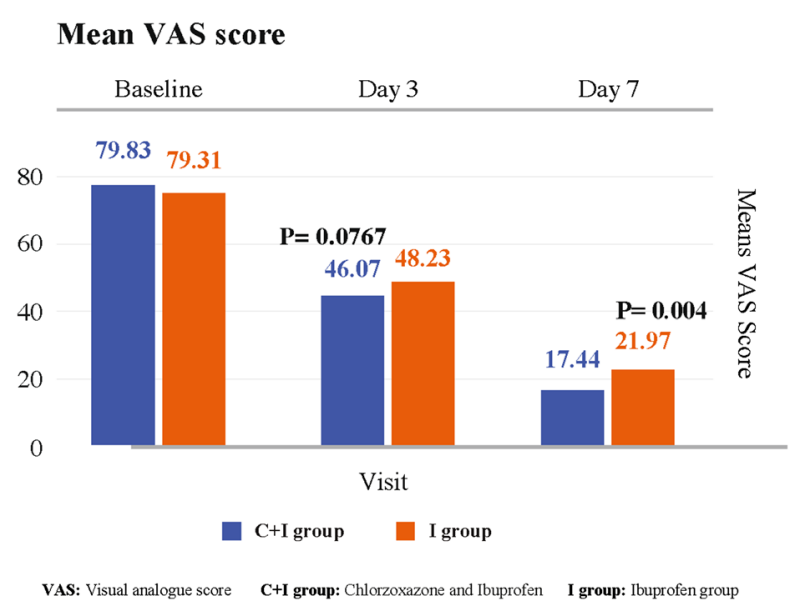

Fig. 1 Visual analogue score during movement at baseline and Days 3 and 7

and none of the patients in the I group reported significant relief. Mild to moderate relief and no relief in pain was reported by $37.93 \%$ and $40.39 \%$ and $61.58 \%$ and $59.61 \%$ patients in the two groups, respectively. Similarly, at $3 \mathrm{~h}$ after dosing, $0.49 \%$ patients in both the treatment groups reported complete relief from pain, while $4.43 \%$ and $4.93 \%$ patients and $88.67 \%$ and $83.74 \%$ patients in the two groups reported significant pain relief and mild to moderate pain relief, respectively. No relief from pain was reported by $6.40 \%$ of $\mathrm{C}+\mathrm{I}$ group patients and $10.84 \%$ of I group patients.

The mean TOTPAR score increased from 0.43 (95\% CI $0.35-0.52)$ at $1 \mathrm{~h}$ to 1.44 (95\% CI 1.34-1.54) after $3 \mathrm{~h}$ and from 0.44 (95\% CI $0.36-0.52)$ at $1 \mathrm{~h}$ to $1.23(1.13-1.33)$ after $3 \mathrm{~h}$ of administration of the study and comparator drugs, respectively (Fig. 2).

Proportion of patients with pain relief post dose in both the groups is as shown in Table 2.

\section{Finger to Floor Distance (FFD)}

The mean FFD scores at baseline were comparable in both the groups. Absolute change in mean FFD from baseline was significantly greater in the $\mathrm{C}+\mathrm{I}$ group than in the I group (135.20 $\mathrm{mm}$ vs $131.00 \mathrm{~mm}$ on day $3(P=0.668)$ and $264.90 \mathrm{~mm}$ vs $249.00 \mathrm{~mm}$ on day 7 $(P=0.328)$.

\section{Lumbar and Dorsal Hypermyotonia}

On Day 7, 58.62\% in the C + I group and $41.87 \%$ of patients in the I-group reported

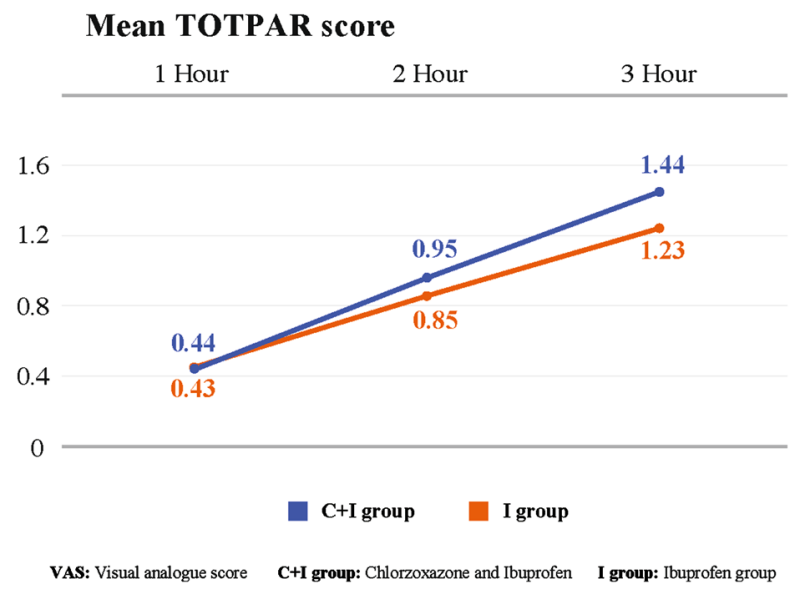

Fig. 2 Mean of total pain relief scores after treatment administration 
Table 2 Proportion of patients with pain relief after drug administration

\begin{tabular}{|c|c|c|c|c|c|c|}
\hline & \multicolumn{2}{|l|}{ After $1 \mathrm{~h}$} & \multicolumn{2}{|l|}{ After $2 \mathrm{~h}$} & \multicolumn{2}{|l|}{ After $3 \mathrm{~h}$} \\
\hline & $C+I$ & I & $\overline{C+I}$ & I & $\overline{C+I}$ & I \\
\hline No relief & $125(61.58 \%)$ & $121(59.61 \%)$ & $59(29.06 \%)$ & $67(33.00 \%)$ & $13(6.40 \%)$ & $22(10.84 \%)$ \\
\hline Mild relief & $68(33.50 \%)$ & $73(35.96 \%)$ & 99 (48.77\%) & $106(52.22 \%)$ & $98(48.28 \%)$ & $123(60.59 \%)$ \\
\hline Moderate relief & $9(4.43 \%)$ & $9(4.43 \%)$ & $41(20.20 \%)$ & $23(11.33 \%)$ & $82(40.39 \%)$ & $47(23.15 \%)$ \\
\hline Significant relief & $1(0.49 \%)$ & $0(0.00 \%)$ & $4(1.97 \%)$ & $7(3.45 \%)$ & $9(4.43 \%)$ & $10(4.93 \%)$ \\
\hline Complete relief & $0(0.00 \%)$ & $0(0.00 \%)$ & $0(0.00 \%)$ & $0(0.00 \%)$ & $1(0.49 \%)$ & $1(0.49 \%)$ \\
\hline
\end{tabular}

$C+I$ Chlorzoxazone + Ibuprofen, $I$ Ibuprofen alone

absence of hypermytonia. At baseline, $22.66 \%$ and $19.21 \%$ patients in the C + I and I groups, respectively had severe hypermyotonia, while no patients had severe hypermyotonia on Day 7. In the $\mathrm{C}+\mathrm{I}$ and I groups, mild to moderate hypermyotonia was present in $76.84 \%$ and $78.32 \%$ at baseline and in $41.38 \%$ and $58.13 \%$ patients on Day 7.

\section{Number of Night Awakenings}

The average numbers of night awakenings due to pain at baseline were $2.81 \pm 1.28$ and $2.66 \pm 1.43$ in $\mathrm{C}+\mathrm{I}$ and I-groups, respectively. On day 7 , these were reduced to $0.34 \pm 0.62$ and $0.46 \pm 0.67$ in the two groups, respectively. There was a significantly higher absolute change in mean of night awakenings in the $\mathrm{C}+\mathrm{I}$ group on Days 3 (1.54 vs. $1.18 ; P<0.001)$ and 7 ( 2.47 vs. $2.20 ; P<0.042)$.

\section{Movement Restriction}

On Day 7, 65.52\% and 50.74\% patients in the $\mathrm{C}+\mathrm{I}$ and I groups, respectively had no restriction in mobility. Though $24.14 \%$ and $22.16 \%$ patients in the $\mathrm{C}+\mathrm{I}$ and I groups had severe to extreme movement restriction at baseline, no patient in any group complained of the same at Day 7. In the two groups, mild to moderate restriction seen in $70.93 \%$ and $72.42 \%$ patients, respectively, at baseline and $34.48 \%$ and $49.26 \%$ patients, respectively, on Day 7 .

Table 3 shows patients with restriction of function due to pain at rest and with movement.

\section{Sensory Disturbances}

At baseline, tingling sensation was seen in $13.30 \%$ and $15.76 \%$ patients in the $\mathrm{C}+\mathrm{I}$ and I-groups, respectively. On day $7,1.48 \%$ and

Table 3 Proportion of patients with restriction of function due to pain at rest and movement

\begin{tabular}{|c|c|c|c|c|c|c|c|c|}
\hline & \multicolumn{4}{|c|}{ Pain at rest } & \multicolumn{4}{|c|}{ Pain during movement } \\
\hline & \multicolumn{2}{|c|}{ Baseline } & \multicolumn{2}{|l|}{ Day 7} & \multicolumn{2}{|c|}{ Baseline } & \multicolumn{2}{|l|}{ Day 7} \\
\hline & $\begin{array}{l}\mathrm{C}+\mathrm{I} \\
(\%)\end{array}$ & I (\%) & $\begin{array}{l}\mathrm{C}+\mathrm{I} \\
(\%)\end{array}$ & I (\%) & $\begin{array}{l}\mathrm{C}+\mathrm{I} \\
(\%)\end{array}$ & I (\%) & $\begin{array}{l}\mathrm{C}+\mathrm{I} \\
(\%)\end{array}$ & I $(\%)$ \\
\hline Not at all & 4.43 & 6.90 & 90.64 & 82.27 & 4.43 & 4.43 & 50.74 & 39.41 \\
\hline Mild, no restriction of function & 48.28 & 45.81 & 8.37 & 15.76 & 16.75 & 25.12 & 48.28 & 52.71 \\
\hline Moderate, some restriction of function & 28.57 & 33.99 & 0.99 & 1.97 & 42.86 & 38.42 & 0.99 & 7.88 \\
\hline Severe, significant restriction of function & 18.72 & 12.81 & 0.00 & 0.00 & 27.09 & 24.14 & 0.00 & 0.00 \\
\hline $\begin{array}{l}\text { Extreme, complete restriction of } \\
\text { function }\end{array}$ & 0.00 & 0.49 & 0.00 & 0.00 & 8.87 & 7.88 & 0.00 & 0.00 \\
\hline
\end{tabular}

$C+I$ Chlorzoxazone + Ibuprofen, $I$ Ibuprofen alone 
$3.45 \%$ patients in the two groups had tingling sensation. Numbness was seen in $28.57 \%$ patients in the $\mathrm{C}+\mathrm{I}$ group and $33.00 \%$ patients in the I group at baseline and $1.48 \%$ patients in the $\mathrm{C}+\mathrm{I}$ group and $4.43 \%$ patients in the I group on Day 7 . In the $\mathrm{C}+\mathrm{I}$ group, paresthesia was completely resolved on Day 7 . In the I group, $8.87 \%$ and $2.46 \%$ patients had paresthesia at baseline and Day 7, respectively.

\section{Global Assessment of Response to Therapy}

On Day 7, 94.08\% patients in the C + I group and $77.33 \%$ patients in the I group achieved excellent to good response and average response was attained in $5.91 \%$ and $22.66 \%$ in the two groups, respectively (Table 4).

\section{Safety and Tolerability}

Safety analyses were done for 203 patients in each group. Minor AEs were reported in 15 patients (nine patients in $\mathrm{C}+\mathrm{I}$ group vs six patients in I-group). Gastritis was reported by six patients ( 4 vs 2 ) and fever by four patients ( 3 vs 1$)$. In the $\mathrm{C}+\mathrm{I}$ group, one patient reported severe gastritis. Stomach pain and cold was reported in one patient each in the I-group. Headache was reported by one patient each in both the groups. No SAEs were reported during the study. Concomitant medications were used to treat AEs and all AEs attained resolution. AEs did not necessitate withdrawal of study drug in any patient. There were no significant drug-related changes in laboratory parameters or vital signs with both the study treatments.
Global Assessment of Tolerability to Therapy

At the end of the study, excellent to good tolerability was observed in $96.05 \%$ patients in $\mathrm{C}+\mathrm{I}$ group and $89.65 \%$ patients in I-group (Table 4).

\section{DISCUSSION}

Combination therapy with skeletal muscle relaxants and NSAID or acetaminophen is beneficial for pain relief in patients with LBP [20]. We have evaluated the effectiveness and safety of a FDC of chlorzoxazone and ibuprofen in comparison to ibuprofen alone in Indian patients with acute LBP. Several studies have evaluated combination therapy with NSAIDs and muscle relaxants in patients with musculoskeletal conditions. In a double-blind study $(n=183)$, combination therapy with chlorzoxazone and acetaminophen was superior to the individual drugs alone in relieving pain and spasm in patients with musculoskeletal back conditions. Faster onset of relief in symptoms was reported with the combination therapy (Day 2) when compared to acetaminophen (Day 4 ). By the end of the study (Day 6), complete remission of symptoms occurred in all patients who received combination therapy. However, approximately $40-50 \%$ patients treated with acetaminophen still had pain or spasm by Day 6 [9]. In another study in patients with skeletal muscle spasm, combination therapy with chlorzoxazone and acetaminophen resulted in $88.6 \%$ reduction in pain severity when

Table 4 Global assessment of response and tolerability to therapy at day 7

\begin{tabular}{llcccc}
\hline & \multicolumn{2}{l}{ Global assessment of response to therapy $($ GART) } & & \multicolumn{2}{l}{ Global assessment of tolerability to therapy (GATT) } \\
\cline { 2 - 3 } & $\mathbf{C}+\mathbf{I}$ & $\mathbf{I}$ & $64(31.52 \%)$ & $112(55.17 \%)$ & I \\
\hline Excellent & $97(47.78 \%)$ & $93(45.81 \%)$ & $83(40.88 \%)$ & $78(38.42 \%)$ \\
Good & $94(46.30 \%)$ & $46(22.66 \%)$ & & $7(3.44 \%)$ & $104(51.23 \%)$ \\
Average & $12(5.91 \%)$ & $0(0.00 \%)$ & $1(0.49 \%)$ & $21(10.34 \%)$ \\
No & $0(0.00 \%)$ & $0(0.00 \%)$ & $0(0.00 \%)$ & $0(0.00 \%)$ \\
Worse & $0(0.00 \%)$ & &
\end{tabular}

$C+I$ Chlorzoxazone + Ibuprofen, $I$ Ibuprofen alone 
compared to $75.1 \%$ reduction with methocarbamol and aspirin combination [21].

In our study, there was $78.2 \%$ reduction in pain severity with the combination of chlorzoxazone and ibuprofen on day 7 as compared to $72.3 \%$ reduction with ibuprofen alone. There was a significant increase in mean SPID from 17.51 at baseline to 300.82 at day 7 in the $\mathrm{C}+\mathrm{I}$ group. In an open label study comparing ibuprofen alone with combination of ibuprofen and paracetamol for the treatment of acute LBP, ibuprofen lead to $66.2 \%$ reduction in pain intensity from baseline to day 10 of treatment, which is lower than the findings in $(72.3 \%)$ our study [22].

Superior analgesia with ibuprofen as compared to other NSAIDS has been established in several studies [23-25]. In the IPSO (Ibuprofen, Paracetamol Study in Osteoarthritis) study, the SPID over $6 \mathrm{~h}$ after the first dose was significantly higher in the ibuprofen group than in the paracetamol group $(P=0.046)$. Over 14 days, pain intensity was further decreased and was significantly lower in the ibuprofen group than in the paracetamol group $(P<0.05)$ [23].

Ibuprofen has been compared to celecoxib, codeine, and acetaminophen for pain relief. In a randomized controlled double-blind study in patients with acute pain $(n=105)$, no significant differences in pain intensity were reported with celecoxib $200 \mathrm{mg}$ and $400 \mathrm{mg}$ and ibuprofen $600 \mathrm{mg}$. Change in VAS at $5 \mathrm{~h}$ was $-23.9 \mathrm{~mm}$ in the ibuprofen group, and $16.2 \mathrm{~mm}$, and $-12.5 \mathrm{~mm}$ in celecoxib $200 \mathrm{mg}$ and $400 \mathrm{mg}$ groups, respectively [24]. In another study, patients with musculoskeletal pain had a greater improvement in pain score in the ibuprofen group $(-24 \mathrm{~mm})$ than those in codeine $(-11 \mathrm{~mm})$ and acetaminophen groups $(-12 \mathrm{~mm})$ at $60 \mathrm{~min}$ [25].

Our study has demonstrated greater effectiveness of chlorzoxazone and ibuprofen fixed dose combination as compared to ibuprofen in patients with acute LBP. FDCs of other muscle relaxants with ibuprofen have not reported favorable outcomes for pain relief. In a study comparing FDC of cyclobenzaprine and ibuprofen with ibuprofen in acute myofascial strain $(n=102)$, the differences in mean VAS scores over $48 \mathrm{~h}$ of treatment were not statistically significant $(P=0.962)$. The addition of cyclobenzaprine to ibuprofen did not improve analgesia and was associated with central nervous system side effects [26].

Besides pain, common complaints with LBP include loss of mobility and sleep and sensory disturbances. We evaluated the effect of the study medications on these parameters. In our study, secondary efficacy analyses consistently supported a higher efficacy of combination than monotherapy; a greater improvement in FFD score (almost $70.4 \%$ vs. $63.4 \% ; P=0.0001$ ) and a greater improvement in night awakenings due to pain $(87.9 \%$ vs $82.7 \% ; P=0.0001)$. There was a marked reduction in hypermyotonia, mobility restriction, pain at rest and movement, sensory disturbances post study drug administration in the $\mathrm{C}+\mathrm{I}$ group. The global efficacy assessments showed that response to therapy was comparatively better perceived in patients receiving combination drug than monotherapy $(94.8 \%$ vs $77.33 \%)$.

Both C + I and I were safe and well tolerated for the treatment of acute LBP. C + I had better tolerability than I by GATT. Common adverse events were gastritis, stomach pain, fever, cold, and headache. None of the adverse events reported were serious in nature.

Treatment with chlorzoxazone $500 \mathrm{mg}$ and ibuprofen $400 \mathrm{mg}$ in thrice daily dosing for 7 days is safe and efficacious in patients of acute LBP with an accompanying muscle spasm. However, the FDC should not be used in patients with acute LBP with no accompanying muscle spasm, e.g., LBP due to degenerative conditions like osteoporosis or osteoarthritis. Treatment should be limited to short-term targeting the acute phase of LBP and associated muscle spasm. Upon resolution of the acute phase, more definitive targeted treatment should be initiated based upon the cause of the LBP. Results of our study may inform the choice of therapy in acute LBP in clinical practice. Additional benefits of using the combination in the treatment of acute LBP are improved treatment compliance and convenience of dosage. However, our study is associated with implied limitations of an open-label study design in a small sample of patients. Acute LBP is widely prevalent in the population and results for 406 
patients in our study cannot be generalized for the whole population. Moreover, our study did not include a placebo-control arm. This makes it difficult to confirm the relief in pain attributable to the given treatment. LBP may be self-limiting and recovery is a component to the natural history of the condition. In our study, only $0.49 \%$ of patients in C + I group and none of the patients in the I group reported significant relief in pain at $1 \mathrm{~h}$ after dosing. This implies the need for a placebo control to confirm the efficacy of the given medication. Our study also does not aim to explore any benefits of lowering the NSAID dosage as patients in both treatment arms received $400 \mathrm{mg}$ of ibuprofen. This attribute may be explored in future studies. We have included only patients with acute LBP and accompanying muscle spasm which is a common clinical problem that requires interruption of the pain-spasm-pain cycle [4]. However, the treatment with $\mathrm{C}+\mathrm{I}$ may be beneficial in other acute pains which are accompanied with muscle spasms, e.g., sprains in the neck, arms, or legs. Evaluation of this FDC in other indications may be done in future studies. Well-controlled studies with adequate sample size should be conducted to confirm the efficacy and safety of the FDC of chlorzoxazone and ibuprofen.

\section{CONCLUSION}

The results of our study suggest that chlorzoxazone is a useful adjunct to ibuprofen in the treatment of acute LBP in general practice. The FDC had superior efficacy to ibuprofen monotherapy. Both the study treatments were safe and well-tolerated in the studied population.

\section{ACKNOWLEDGEMENTS}

The authors also thank the participants of the study.

Funding. Sponsorship for this study and article processing charges were funded by Dr.
Reddy's Laboratories Ltd. All authors had full access to all of the data in this study and take complete responsibility for the integrity of the data and accuracy of the data analysis.

Medical Writing and Editorial Assistance. The authors thank Dr. Tarveen Jandoo, MD, MBA, an independent medical writer, for medical writing support and editorial assistance for the preparation of this article. The support of this assistance was funded by Dr. Reddy's Laboratories Ltd.

Authorship. All named authors meet the International Committee of Medical Journal Editors (ICMJE) criteria for authorship for this manuscript, take responsibility for the integrity of the work, and have given final approval for the version to be published.

Disclosures. Suhas Khandarkar is an employee of Dr. Reddy's Laboratories Ltd. Amit Garg is an employee of Dr. Reddy's Laboratories Ltd. Himanshu D. Patel, R. B. Uppin, A. Ramakrishnam Naidu and Y. Ratnakar Rao have nothing to disclose.

Compliance with Ethics Guidelines. All procedures performed in studies involving human participants were in accordance with the ethical standards of the institutional and/or national research committee and with the 1964 . Helsinki declaration and its later amendments or comparable ethical standards. Informed consent was obtained from all individual participants included in the study. Additional informed consent was obtained from all individual participants for whom identifying information is included in this article.

Data Availability. The datasets generated during and/or analyzed during the current study are available from the corresponding author on reasonable request.

Open Access. This article is distributed under the terms of the Creative Commons AttributionNonCommercial 4.0 International License (http://creativecommons.org/licenses/by-nc/4. $0 /$ ), which permits any noncommercial use, 
distribution, and reproduction in any medium, provided you give appropriate credit to the original author(s) and the source, provide a link to the Creative Commons license, and indicate if changes were made.

\section{REFERENCES}

1. Patrick N, Emanski E, Knaub MA. Acute and chronic low back pain. Med Clin N Am. 2014;98:777-89.

2. May S. Self-management of chronic low back pain and osteoarthritis. Nat Rev Rheumatol. 2010;6(4):199-209.

3. Dagenais S, Caro J, Haldeman S. A systematic review of low back pain cost of illness studies in the United States and internationally. Spine J. 2008;8(1):8-20.

4. Frydrych V. Skeletal Muscle Relaxants. Drug Class Review. 2016. https://medicaid.utah.gov/ pharmacy/ptcommittee/files/Criteria\%20Review\% 20Documents/2016/2016.02\%20Skeletal\% 20Muscle\%20Relaxant\%20Class\%20Review.pdf. Accessed on: 01 Oct, 2018.

5. Chou R, Deyo R, Friedly J, Skelly A, Weimer M, Fu R. Systemic pharmacologic therapies for low back pain: a systematic review for an American College of Physicians Clinical Practice Guideline. Ann Intern Med. 2017;166:480-92.

6. NICE guideline. Low back pain and sciatica in over $16 \mathrm{~s}$ : assessment and management. Published 30 NOV 2016. https://www.nice.org.uk/guidance/ ng59. Accessed 01 Oct 2018.

7. Witenko C, Moorman-Li R, Motycka C, et al. Considerations for the appropriate use of skeletal muscle relaxants for the management of acute low back pain. P\&T. 2014;39(6):427-35.

8. Kumar S, Rani S, Siwach R, Verma P. To compare the efficacy and safety of fixed dose combination of thiocolchicoside and aceclofenac versus chlorzoxazone, aceclofenac and paracetamol in patients with acute lower backache associated with muscle spasm. Int J Appl Basic Med Res. 2014;4(2):101-5.

9. Vernon WO. A double-blind evaluation of parafon forte in the treatment of musculo-skeletal back conditions. Curr Ther Res. 1972;14(12):801-6.

10. Scheiner JJ. Evaluation of a combined muscle relaxant-analgesic as an effective therapy for painful skeletal muscle spasm. Curr Ther Res. 1972;14(4):168-77.
11. Berry H, Hutchinson DR. Tizanidine and ibuprofen in acute low-back pain: results of a double-blind multicentre study in general practice. J Int Med Res. 1988;16:83-91.

12. SirdaludTernelin Asia-Pacific Study Group. Efficacy and gastroprotective effects of tizanidine plus diclofenac versus placebo plus diclofenac in patients with painful muscle spasms. Curr Ther Res. 1998;59:13-22.

13. Scheiner JJ. Muscle relaxants: chlorzoxazone compared with diazepam (a double blind study). Curr Therap Res. 1976;19(1):51-7.

14. Christensen S, Paluch E, Jayawardena S, Daniels S, Meeves $S$. Analgesic efficacy of a new immediaterelease/extended-release formulation of ibuprofen: results from single- and multiple-dose postsurgical dental pain studies. Clin Pharmacol Drug Devel. 2017;6(3):302-12.

15. Moore N, Van Ganse E, Le Parc J-M, et al. The PAIN Study (Paracetamol, Aspirin and Ibuprofen New Tolerability study): a large-scale randomized clinical trial comparing the tolerability of aspirin, ibuprofen and paracetamol for short-term analgesia. Clin Drug Invest. 1999;18:89-98.

16. Le Parc JM, Van Ganse E, Moore N, Wall R, Schneid $\mathrm{H}$, Verrie're F. Comparative tolerability of paracetamol, aspirin and ibuprofen for short-term analgesia in patients with musculoskeletal conditions : results in 4291 patients. Clin Rheumatol. 2002;21: 28-31.

17. Singla N, Hunsinger M, Chang PD, et al. Assay sensitivity of pain intensity versus pain relief in acute pain clinical trials: ACTTION systematic review and meta-analysis. J Pain. 2015;16(8):683-91.

18. Heikkilä S, Viitanen JV, Kautiainen H, Kauppi M. Sensitivity to change of mobility tests; effect of short term intensive physiotherapy and exercise on spinal, hip, and shoulder measurements in spondyloarthropathy. J Rheumatol. 2000;27(5): 1251-6.

19. Dreiser RL, Marty M, Ionescu E, Gold M, Liu JH. Relief of acute low back pain with diclofenac-K $12.5 \mathrm{mg}$ tablets: a flexible dose, ibuprofen $200 \mathrm{mg}$ and placebo-controlled clinical trial. Int J Clin Pharmacol Thera. 2003;41(9):375-85.

20. Chou R, Huffman LH. Medications for acute and chronic low back pain: a review of the evidence for an American Pain Society/American College of Physicians Clinical Practice Guideline. Ann Intern Med. 2007;147:505-14. 
21. Gready DM. Parafon forte versus Robaxisal in skeletal muscle disorders: a double blind study. Curr Ther Res. 1976;20(5):666-73.

22. Ostojic P, Radunovic G, Lazovic M, TomanovicVujadinovic S. Ibuprofen plus paracetamol versus ibuprofen in acute low back pain: a randomized open label multicenter clinical study. Acta Reumatol Port. 2017;42:18-25.

23. Boureau F, Schneid H, Zeghari N, Wall R, Bourgeois P. The IPSO study: ibuprofen, paracetamol study in osteoarthritis. A randomised comparative clinical study comparing the efficacy and safety of ibuprofen and paracetamol analgesic treatment of osteoarthritis of the knee or hip. Ann Rheum Dis. 2004;63:1028-34.
24. Salo DF, Lavery R, Varma V, Goldberg J, Shapiro T, Kenwood A. A randomized, clinical trial comparing oral celecoxib $200 \mathrm{mg}$, celecoxib $400 \mathrm{mg}$, and ibuprofen $600 \mathrm{mg}$ for acute pain. Acad Emerg Med. 2003;10:22-30.

25. Clark E, Plint AC, Correll R, Gaboury I, Passi B. A Randomized, controlled trial of acetaminophen, ibuprofen, and codeine for acute pain relief in children with musculoskeletal trauma. Pediatrics. 2007;119(3):56.

26. Turturro MA, Frater CR, D'Amico FJ. Cyclobenzaprine with ibuprofen versus ibuprofen alone in acute myofascial strain: a randomized, double-blind clinical trial. Ann Emerg Med. 2003;41(6):818-26. 